\title{
Online Monitoring for Strychnos Nux-vomica Parching in Sands and Chemical Compositional Analysis by Ultra Performance Liquid Chromatography - Linear Trap Quadrupole -Orbitrap- Mass Spectrometry
}

\author{
Yujie Liu ${ }^{1}$, Ying $\mathrm{Xu}^{1}$, Huaiyao $\mathrm{Qiao}^{2}$, Xiao $\mathrm{Ke}^{2}$, Zhigang $\mathrm{Wu}^{2}$, Tao Sun ${ }^{1}$ and \\ Chunjie Wu ${ }^{1 *}$ \\ ${ }^{1}$ Department of Pharmacy, Chengdu University of Traditional Chinese Medicine, Chengdu, 611137, ${ }^{2}$ Kang Hong \\ Pharmaceutical Group Co, Ltd, Chengdu, 610036, PR China
}

*For correspondence: Email: wuchunjie@gmail.com

Received: 18 June 2014

Revised accepted: 11 September 2014

\begin{abstract}
Purpose: To provide an online and non-contact method to monitor the dynamic temperature of the nuxvomica parching in sands, and also to develop a rapid screening and comparison of the compounds in crude and processed nux-vomica.

Methods: Seeds of nux-vomica were parched in sands by an herbal medicine roaster with an onlinetype and non-contact temperature measurement system (ONTMS). Processing was monitored by ONTMS and the processing temperature was accurately controlled within the range $200-220^{\circ} \mathrm{C}$. Ultra performance liquid chromatography - linear trap quadrupole -orbitrap-mass spectrometry method in positive ionization mode was established in this work. The samples were extracted by ultrasonication with $50 \%$ methanol for 30 min. Chromatographic separation was achieved on an Acquity UPLC HSS T3 column using a gradient program with acetonitrile and $1 \%$ formic acid as the mobile phase and a diode array detector set at $254 \mathrm{~nm}$ for quantification.

Results: The surface color of the processed seeds of nux-vomica were brown or dark brown and the cross-section bulged with small bubble which meets the requirements of Chinese traditional processing methods. Fourteen major compounds from crude and processed nux-vomica were identified simultaneously by HPLC-DAD. According to the MS fragmentation pathways and by comparing with reference literature, the structures of eleven of the compounds were confirmed.

Conclusion: Methods using ONTMS are more accurate for parching nux-vomica in sands and UPLC$L T Q-O r b i t r a p-M S$ is a rapid and straightforward method for compound profiling in crude and processed nux-vomica.
\end{abstract}

Keywords: Strychnos, Nux vomica, Parching in sands, Online-type and non-contact temperature measurement system , Ultra performance liquid chromatography - linear trap quadrupole - orbitrap mass spectrometry, Compound profiling

Tropical Journal of Pharmaceutical Research is indexed by Science Citation Index (SciSearch), Scopus, International Pharmaceutical Abstract, Chemical Abstracts, Embase, Index Copernicus, EBSCO, African Index Medicus, JournalSeek, Journal Citation Reports/Science Edition, Directory of Open Access Journals (DOAJ), African Journal Online, Bioline International, Open-J-Gate and Pharmacy Abstracts

\section{INTRODUCTION}

The dried ripe seeds of Strychnos nux-vomica $L$. are called nux vomica used as a traditional folk medicine in China. It is mainly used to cure diseases such as swelling pain, trauma, rheumatoid arthritis, bone fracture, myasthenia gravis, and facial nerve paralysis [1]. The main chemical composition of Strychno nux-vomica seeds were alkaloids, such as strychnine and 
brucine, which have been proved to be the main bioactive components responsible for the pharmacological and toxic properties [2,3].

The processing of traditional Chinese herbal medicine is a common procedure and usually applied before the prescription. In China, seeds of Strychnos nux-vomica need to be processed in hot sands for toxicity reduction before clinical practice as described in the Chinese pharmacopoeia $[1,4]$. Contents of the major toxic alkaloid were significantly decreased because of the high temperature treatment [5]. Processed Strychnos nux-vomica appears to become more effective than its crude product because toxic alkaloids are transformed into nitrogen oxidation or isoforms derivatives after processing procedure $[5,6]$.

An online-type and non-contact temperature measurement system (ONTMS) was invented by our research team and had been patented (PR China Patent No.: ZL200520200614.0). In the sand parching process of Strychnos nux-vomica, it could display and control the temperature of the herbal medicine roaster.

HPLC-MS method used to analyze the content of strychnine from Strychno nux-vomica seeds and comparison to processed seeds and quantitative determination of strychnine residues in urine have been published $[7,8]$. In this paper, we use ONTMS to display and control the temperature of the herbal medicine roaster in the sand parching process of nux-vomica. Then the changes in the chemical compositions changes from nux-vomica to the sand parching process was analyzed by UPLC-MS method.

\section{EXPERIMENTAL}

\section{Chemicals and reagents}

Seeds of Strychnos nux-vomica were purchased from Sichuan Chinese Medicine Yinpian Company Limited. The sand $(50 \mathrm{~kg})$ were purchased from the local market in Chengdu, passed through sieve for $300-600 \mu m$ and washed clean with water. Acetonitrile, methanol, formic acid of HPLC grade were purchased from Thermo Fisher Scientific (China).

\section{Strychnos nux-vomica parching in sands}

Sand $(300-600 \mu \mathrm{m})$ was placed in a herbal medicine roaster with online-type and noncontact temperature measurement system (ONTMS, Haishan Pharmaceutical Equipment Company Limited. in Hangzhou) for heating. The ONTMS was connected to computer and temperature of processing procedure was collected. The nux-vomica seed were put into roaster when the temperature of sands increased to $210{ }^{\circ} \mathrm{C}$, and then parched for about $8 \mathrm{~min}$ with the roaster temperature set between $200-220$ oC. The roaster was controlled to pour burnt nuxvomica into a sieve to remove the sands, and burnt nux-vomica seeds were obtained.

\section{Sample preparation}

Crude nux-vomica and the burnt sample were powdered by a mill and sieved through a No. 50 mesh sieve (inside diameter $355 \mu \mathrm{m} \pm 13 \mu \mathrm{m}$ ). An amount of $0.5 \mathrm{~g}$ was accurately weighed into $50 \mathrm{~mL}$ conical flask respectively, and $25 \mathrm{~mL}$ of 50 $\%$ methanol was added to each conical flask. The mixtures were placed into an ultrasonic bath $(40 \mathrm{kHz})$ for $30 \mathrm{~min}$ at room temperature and then filtered. The filtrate was diluted to $10 \mathrm{~mL}$ with $50 \%$ methanol and filtered through $0.22 \mu \mathrm{m}$ cellulose membrane filters prior to injection.

\section{UPLC- LTQ-Orbitrap-MS conditions}

UPLC was performed using an UltiMate 3000 UPLC system (Thermo, USA). All samples separation was performed on an ACQUITY UPLC HSS T3 column $(1.8 \mu \mathrm{m}, 2.1 \mathrm{~mm} \times 150$ $\mathrm{mm})$. The mobile phase consisted of $A$ (acetonitrile) and B ( $0.8 \%$ formic acid in aqueous solution). Gradient elution was as follows: $0-2$ $\min , 5 \% \mathrm{~A} ; 2-25 \mathrm{~min}, 5-30 \% \mathrm{~A}$. The injection volume was $1 \mu \mathrm{L}$, and the column temperature was maintained at $30{ }^{\circ} \mathrm{C}$. The flow rate of the mobile phase was $0.2 \mathrm{~mL} /$ min and Photodiode array detector (DAD) detection wavelength was $254 \mathrm{~nm}$.

LTQ Orbitrap Elite MS (Thermo, USA) was operated in positive ionization mode using the following operating parameters: spray voltage 3.5 $\mathrm{kV}$, sheath gas flow rate 35 arb, aux gas flow rate 10 arb, sweep gas flow rate 1 arb, capillary temperature $340{ }^{\circ} \mathrm{C}$, capillary voltage $3.5 \mathrm{kV}$. Accurate mass spectra of $[\mathrm{M}+\mathrm{H}]^{+}$ions were recorded from 50 to $800 \mathrm{~m} / \mathrm{z}$ and collision energy was $35 \mathrm{eV}$.

\section{RESULTS}

\section{Online monitoring of Strychnos nux-vomica parching in sands}

From temperature - time curve collected by ONTMS, the temperature decreases about $40^{\circ} \mathrm{C}$ when the nux-vomica was placed in the herbal medicine roaster. It took about $4 \mathrm{~min}$ before the temperature was back to original and it then took 
4 min for parching with the temperature 200 $220^{\circ} \mathrm{C}$.

In this study, accurate processing methods and ONTMS were used to process the nux-vomica. The surface color of the processed products was brown or dark brown and cross-section bulged with small bubble. These meet the requirements of traditional processing methods of nux-vomica according to Chinese pharmacopoeia.

\section{Optimization of UPLC- LTQ-Orbitrap-MS conditions}

Extraction conditions, including extraction methods, extraction solvents and extraction time were assessed based on single factor experiments in order to obtain optimal extraction efficiency for all the constituents. The optimal extraction efficiency was obtained by ultrasonication extraction with $50 \%$ methanol for $30 \mathrm{~min}$. Photodiode array detector (DAD) was used in UPLC analysis and the optimum monitor wavelength at $254 \mathrm{~nm}$ was selected from the full range spectra by comparing the sample separation under different wavelength. Several binary solvent gradients were compared with respect to separation efficiency of each compound. To enhance peak resolution, formic acid, acetic acid and phosphoric acid were used as modifiers added to the mobile phase. As described in the experimental section, a gradient solvent system with formic acid as modifier was developed after several trials and a total of 13 compounds were detected within 25 min.

In the experiment, the target compounds showed much higher response signals in positive ionization mode than in negative ionization mode. Hence, positive ionization mode was finally selected to detect these compounds. The MS conditions, including spray voltage and collision energy were optimized to achieve better detection of the compounds. As a result, positive ionization mode, spray voltage $3.5 \mathrm{kV}$ and collision energy $35 \mathrm{eV}$ was selected, and results of the UPLC-LTQ-Orbitrap-MS assay was presented in Table 1.

\section{UPLC- LTQ-Orbitrap-MS analysis of authentic compounds}

The processed nux-vomica was compared with the unprocessed sample under the same chromatographic conditions. Ten peaks of unprocessed sample and eleven peaks of processed sample were detected. Based on the recorded $\mathrm{m} / \mathrm{z}$ values and additional fragment information in the positive mode, with reference literatures of strychnos nux-vomica [6,9-14], the peak identification results are shown in Fig 2 and presented in Table 1.

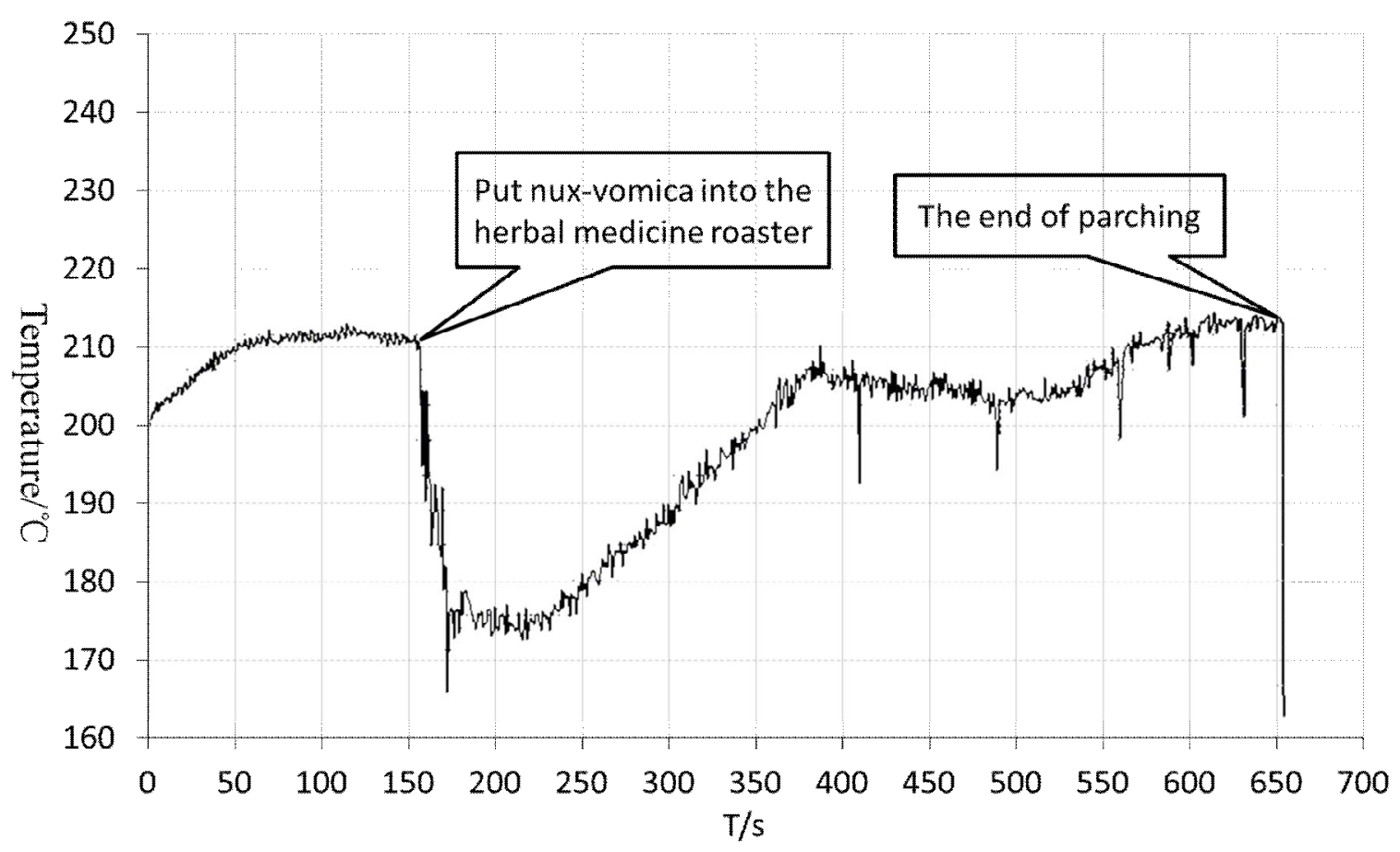

Fig 1: Temperature variation in the sand parching process of nux-vomica 


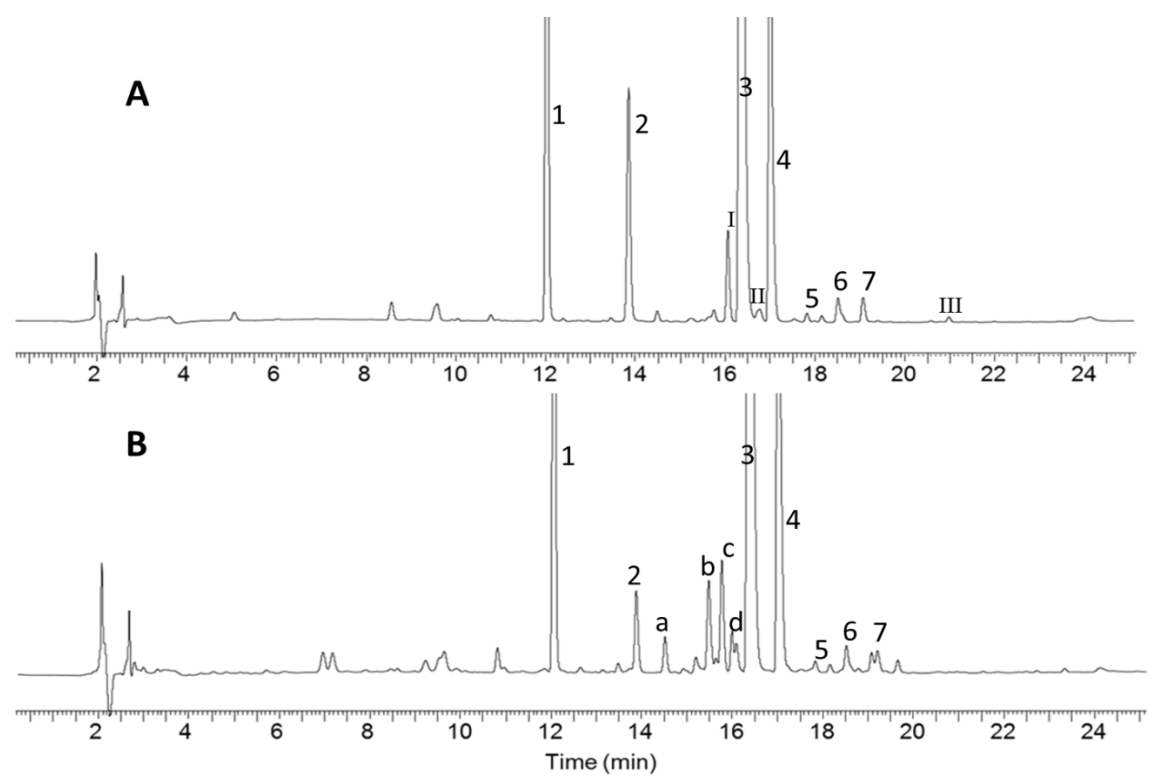

Fig 2: Representative UPLC chromatogram of (A) unprocessed nux-vomica and (B) processed nux-vomica

Table 1: Results of the UPLC-LTQ-Orbitrap-MS assay

\begin{tabular}{|c|c|c|c|c|}
\hline Peak no. & $\mathrm{T}_{\mathrm{R}}(\mathrm{min})$ & {$[\mathrm{M}+\mathrm{H}]^{+\prime} /(\mathrm{m} / \mathrm{z})$} & Fragment ions(+)/(m/z) & Identification \\
\hline 1 & 12.09 & 394.1726 & $341,215,197,179,151,137$ & Unidentified \\
\hline 2 & 13.92 & 355.1039 & $337,253,181,163,145,117$ & Chlorogenic acid \\
\hline a & 14.54 & 349.1926 & $331,306,210,184$ & Strychnine-N-oxide \\
\hline b & 15.53 & 349.1926 & $321,264,206,183$ & Isostrychnine- $\mathrm{N}$-oxide \\
\hline c & 15.85 & 335.1768 & $317,272,197,144$ & Isostrychnine \\
\hline d & 16.07 & 395.1983 & $367,332,280,204,122$ & Isobrucine \\
\hline I & 16.17 & 408.1883 & & Unidentified \\
\hline 3 & 16.48 & 335.1769 & $307,264,222,184,153,122$ & Strychnine \\
\hline II & 16.83 & 411.1933 & $376,320,204,112$ & Pseudobrucine \\
\hline 4 & 17.04 & 395.1983 & $367,324,282,244,190,146,108$ & Brucine \\
\hline 5 & 17.89 & 365.1876 & $347,308,264,219,179,148$ & Methyl pseudostrychnine \\
\hline 6 & 18.65 & 365.1875 & $337,294,252,214,166,124$ & 3-methoxystrychine \\
\hline 7 & 19.15 & 381.1835 & $363,324,306,280,252$ & Vomicine \\
\hline III & 21.11 & 443.1988 & & Unidentified \\
\hline
\end{tabular}

Fragmentation pathway was analyzed for the chemical profiling of the sample. Seven peaks (1, $2,3,4,5,6$ and 7 ) in the unprocessed sample were the same as in the processed sample. Peak 1 (m/z 394.1726) was unidentified, peak 2-7 was respective for Chlorogenic acid, Strychnine, Brucine, Methyl pseudostrychnine, 3-methoxy strychnine and Vomicine.

Four new peaks (a, b, c and d) in the processed sample were identified: peak a was Strychnine$\mathrm{N}$-oxide, peak b was Isostrychnine- $\mathrm{N}$-oxide, peak c was isostrychnine and peak $d$ is isobrucine. Three peaks (I, II and III) in the unprocessed sample disappeared, peak II was Pseudobrucine, peak I (m/z 408.1883)and peak II (443.1988) were unidentified.

\section{DISCUSSION}

The traditional processing methods of nuxvomica described in the Chinese pharmacopoeia were mainly relied on experience and the temperature of parching in sands was determined manually. The ONTMS provided a method to measure the dynamic temperature change during processing procedure. Based on this, a method of accurate temperature control to process nux-vomica was established. The processed products have stable quality due to the accurate control and are also conductive to the inheritance of traditional processing methods. A sensitive and reliable UPLC-LTQ-Orbitrap-MS method has been developed for the determination of compounds in crude and processed nux-vomica. Two peaks (II and III) were not detected in the sample of crude nux- 


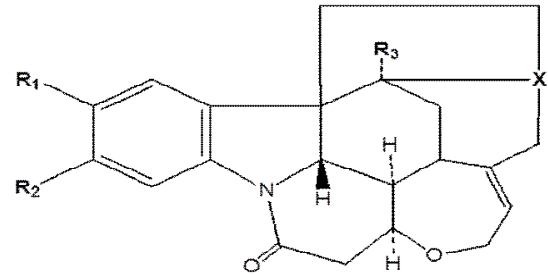

$\begin{array}{llllll} & & \mathrm{R}_{1} & \mathrm{R}_{2} & \mathrm{R}_{3} & \mathrm{x} \\ \text { Strychnine } & (3) & \mathrm{H} & \mathrm{H} & \mathrm{H} & \mathrm{N} \\ \text { Brucine } & (4) & \mathrm{OCH}_{3} & \mathrm{OCH}_{3} & \mathrm{H} & \mathrm{N} \\ \text { Strychnine-N-oxide } & (a) & \mathrm{H} & \mathrm{H} & \mathrm{H} & \mathrm{N}-\mathrm{O} \\ \text { Pseudobrucine } & (i 1) & \mathrm{OCH}_{3} & \mathrm{OCH}_{3} & \mathrm{OH} & \mathrm{N} \\ \text { 3-methoxy strychnine } & (6) & \mathrm{H} & \mathrm{OCH}_{3} & \mathrm{H} & \mathrm{N}\end{array}$

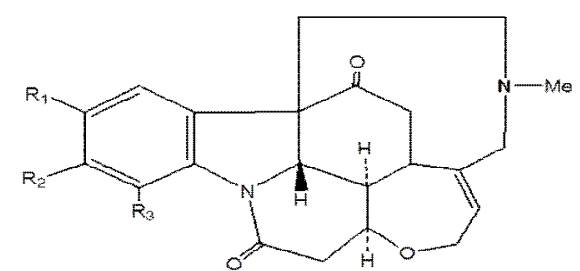

$$
\begin{array}{lllll} 
& & R_{1} & R_{2} & R_{3} \\
\text { Methyl pseudostrychnine } & \text { (5) } & H & H & H \\
\text { Vomicine } & (7) & H & H & O H
\end{array}
$$

Fig. 3 Structure of compounds

vomica, further investigation on the corresponding structures (Fig 3) would be of profound significance. Meanwhile, development of new separation techniques are necessary to distinguish the isomer compounds. Nevertheless, the direct analysis by UPLC-LTQ-Orbitrap-MS provided a rapid screening and comparison on the compounds in the seeds of crude and processed nux-vomica.

\section{CONCLUSION}

ONTMS provided an online and non-contact method to monitor the dynamic temperature of the nux-vomica parching in sands; UPLC-LTQOrbitrap-MS is a rapid and straightforward method to generate compounds profiles in the seeds of crude and processed nux-vomica.

\section{ACKNOWLEDGEMENT}

This work was supported by TCM Industryspecific Project of 2010, 2012(No.201107008) and Three-year action development Plan of TCM in Shanghai(No. ZYSNXD-CC-BZH).

\section{REFERENCES}

1. Ch PC. Chinese pharmacopoeia, Vol. 1. Beijing: Chemical Industry Press; 2010. 47p.

2. Yin W, Wang TS, Yin FZ, Cai BC. Analgesic and antiinflammatory properties of brucine and brucine $\mathrm{N}$ -

\begin{tabular}{|c|c|c|c|}
\hline & & $R_{1}$ & $\mathrm{R}_{2}$ \\
\hline Isostrychnine & (c) & $H$ & $H$ \\
\hline Isobrucine & (d) & $\mathrm{OCH}_{3}$ & $\mathrm{OCH}_{3}$ \\
\hline
\end{tabular}

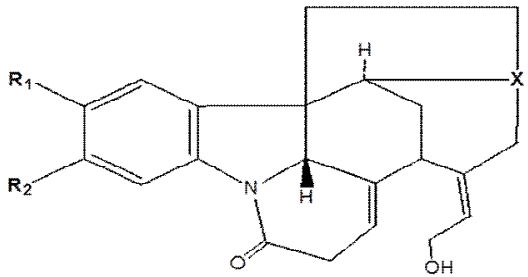<smiles>O=C(C=CC1=CC(O)=C(O)CC1)O[C@H]1CC(O)(C(=O)O)CC(O)C1O</smiles>

Chlorogenic acid(2) oxide extracted from seeds of Strychnos nux-vomica. J Ethnopharmacol2003; 88: 205-214.

3. Chen J, Wang X, Qu YG, Chen ZP, Cai H, Liu X, Xu F, Lu TL, Cai BC. Analgesic and anti-inflammatory activity and pharmacokinetics of alkaloids from seeds of Strychnos nux-vomica after transdermal administration:Effect of changes in alkaloid composition. J Ethnopharmacol2012; (139): 181-188.

4. Cai BC, Hattori M., Namba T. Processing of nux vomica.

II. Changes in alkaloid composition of the seeds of Strychnos nux-vomica on traditional drug-processing. Chem Pharm Bull (Tokyo) 1990; 38(5): 1295-1298.

5. Cai BC, Yang XW, Hattori M, Namba T. Processing of nux vomica. I. Four new alkaloids from the processed strychnos nux-vomica. Shoyakugaku Zasshi 1990; 41(1): 42-46.

6. Wu W, Qiao CF, Liang ZT, Xu HX, Zhao ZZ, Cai ZW. Alkaloid profiling in crude and processed Strychnos nux-vomica seeds by matrix-assisted laser desorption/ionization-time of flight mass spectrometry. J Pharmaceut and Biomed Analysis 2007; 45: 430-436.

7. Choi YH, Sohn YM, Kim CY, Oh KY, Kim J. Analysis of strychnine from detoxified Strychno nux-vomica seeds using liquid chromatography-electrospray mass spectrometry. J Ethnopharmacol 2004; 93: 109112.

8. Van Eenoo $P$, Deventer $K$, Roels $K$, Delbeke FT. Quantitative LC-MS determination of strychnine in urine after ingestion of a Strychnos nux-vomica preparation and its consequences in doping control. Forensic Sci Int 2006; 164: 159-163. 
9. Cai BC, Wu H, Yang SW, Hattori M, Nainba T. Analysis of spectral data for 13CNMR of sixteen strychnos alkloids. Acta Pharm Sin (China) 1994; 29(1): 44-48.

10. Yan J, Liu, ZQ, Zhu HG, Liu SY. Analysis of Two Trace Alkaloid Isomers in Strychnos nux-vomical by Electrospray lonization Tandem Mass Spectrometry. Acta Chimica Sinica (China) 2007; 65(1): 49-52.

11. Zhang JY, Zhang Q, Zhang F, Zhang HX, Yin PH, Tu PF. Characterization Four Kinds of Alkaloids in Strychnos nux-vomica by HPLC-ESI-MS-MS. Chinese Journal of Experimental Traditional Medical Formulae 2013; 19(9): 147-151.
12. Cai BC, Wu H. Strychnine heating reaction. Chin $J$ of Chin Mater Med 1994; 29(5): 302-304.

13. Zhang JY, Li N, Hu K, Tu PF. Chemical constituents from processed seeds of Strychnos nux-vomica. J Chin Pharm Sci 2012; 21: 187-191.

14. Hu FL, Deng CH, Liu Y, Zhang XM. Quantitative determination of chlorogenic acid in Honeysuckle using microwave-assisted extraction followed by nano-LC-ESI mass spectrometry. Talanta 2009; 77: 1299-1303. 